\title{
Consolidated bioprocessing of lignocellulose by a microbial consortium $\uparrow$
}

Cite this: Energy Environ. Sci., 2014, 7, 1446

Received 22nd May 2013

Accepted 13th January 2014

DOI: $10.1039 / \mathrm{c} 3 e e 41753 \mathrm{k}$

www.rsc.org/ees

\author{
Simone Brethauert and Michael Hanspeter Studer $\ddagger^{*}$
}

Lignocellulosic biomass is uniquely suited as a sustainable feedstock for the biotechnological production of alternative fuels and chemicals. However, due to the biomass recalcitrance, the enzymatic conversion process is complex and needs to be simplified. To this end, we developed a process, which allows the consolidated bioprocessing of lignocellulose to ethanol in a single multi-species biofilm membrane reactor featuring both aerobic and anaerobic conditions necessary for the simultaneous fungal cellulolytic enzyme production and alcoholic yeast fermentation of the hydrolysis-derived sugars. The general feasibility of the concept was successfully demonstrated by producing ethanol with a $67 \%$ yield from undetoxified whole slurry dilute acid pretreated wheat straw by the combined action of Trichoderma reesei, Saccharomyces cerevisiae and Scheffersomyces stipitis. The results achieved underscore the potential of the process as a versatile cheap sugar platform for the production of fuels and chemicals based on lignocellulosic biomass by specifically compiled consortia of industrially proven robust microorganisms.

\section{Broader context}

Biofuels made from lignocellulosic biomass have the potential to be useful elements in the overall approach to tackle the issues of climate change and sustainable energy supply. However, this potential can only be unlocked if they are cost competitive to petroleum and starch and sucrose based biofuels. For the biochemical conversion route comprising the three main steps of physicochemical pretreatment, enzymatic hydrolysis and fermentation, the following objectives have to be addressed: (i) development of an integrated process without washing and detoxification steps, (ii) reduction of cellulase costs, (iii) improving hexose and pentose sugar co-utilization, and (iv) overcoming the plants' recalcitrance. As an alternative to employing one genetically engineered superior biocatalyst capable of both degrading biomass and producing biofuel for consolidated bioprocessing (CBP), we present in this paper a novel microbial consortium based approach to tackle issues (i) to (iii). We developed a membrane biofilm reactor, which, as a unique feature, enables the coexistence of aerobic and anaerobic conditions at the same time. This allows the coexistence of the two common "workhorses" of the cellulosic ethanol industry in one system: the aerobic hydrolytic enzyme producing fungus Trichoderma reesei and the anaerobic ethanol producing yeast Saccharomyces cerevisiae.

\section{Introduction}

Lignocellulosic biomass such as wood, agricultural residues or dedicated energy crops constitutes the most abundant renewable organic compound in the biosphere. ${ }^{1}$ It is a promising source of mixed sugars for fermentation to biofuels and chemicals thereby reducing today's addiction to petroleum with its associated issues such as global warming, greenhouse gas emissions and uncertain sources. ${ }^{2}$ The biochemical route from lignocellulose to the product of choice comprises three main steps: physicochemical pretreatment, enzymatic hydrolysis of

Swiss Federal Institute of Technology (ETH) Zurich, Institute of Process Engineering, 8092 Zurich, Switzerland. E-mail: michael.studer@ipe.mavt.ethz.ch; Fax: +41 44 632 1325; Tel: +41446322488

$\dagger$ Electronic supplementary information (ESI) available. See DOI: $10.1039 / \mathrm{c} 3 e e 41753 \mathrm{k}$

$\$$ Present address: Bern University of Applied Sciences, School of Agricultural, Forest and Food Sciences, 3052 Zollikofen, Switzerland. E-mail: studer.michael@alumni.ethz.ch; Fax: +41 31910 22 99; Tel: +41 319102936. the sugar polymers and the fermentation of the derived sugars..$^{3,4}$ Due to the released toxins during pretreatment and the difficulties of the simultaneous fermentation of C5 and C6 sugars, the overall process is complemented by several solid-liquid separation, washing and polishing steps (Fig. 1). ${ }^{5}$ To reduce capital and processing costs, simplification of the process scheme and integration of as many unit operations as possible, often termed as consolidated bioprocessing (CBP), is necessary. ${ }^{6}$ The biological approach to CBP employs one genetically engineered superior biocatalyst capable of both degrading the biomass and producing biofuels. ${ }^{7}$ Although considerable progress has been made in recent years by engineering several hosts to produce a range of different biofuels from lignocellulose, ${ }^{8-10}$ most studies have a proof of concept character with low titers achieved from model celluloses (Table 1) and currently no commercially viable CBP organism has been reported. ${ }^{11}$

Alternatively, CBP could also be performed by a microbial consortium as it is usually the case in nature, e.g. in the soil or in the digestive tracts of termites or ruminant animals. ${ }^{12-14}$ In 


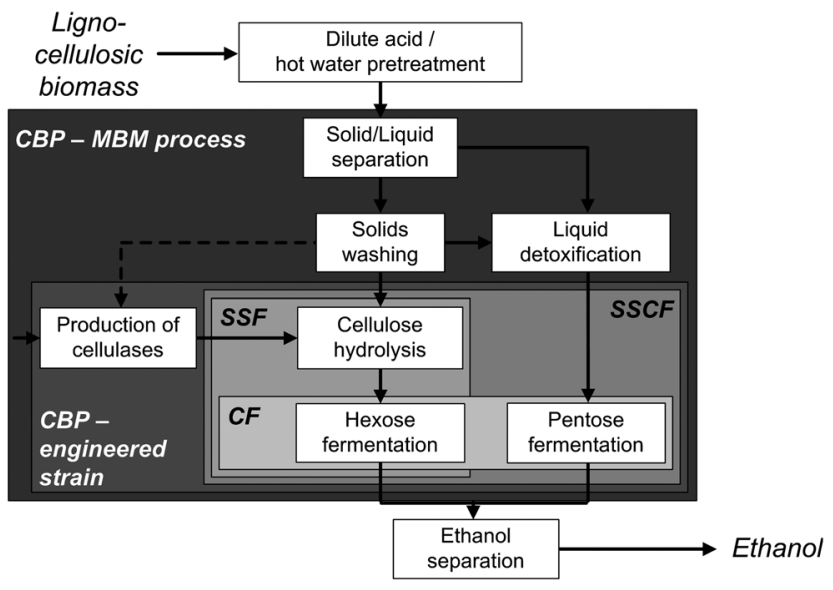

Fig. 1 Block diagram of biotechnological ethanol production from lignocellulosic biomass. Integration possibilities are shown inside the boxes: CF, co-fermentation; SSF, simultaneous saccharification and fermentation; SSCF, simultaneous saccharification and co-fermentation; CBP, consolidated bioprocessing; MBM, multi-species biofilm membrane process.

consortia, synergies may exist that can result in more efficient substrate utilization and increased product yield. ${ }^{13}$ Furthermore, the often encountered loss of overall capacity and robustness of the biocatalyst due to the importation of genes for exogenous functions can be avoided by a combination of specialized natural strains. ${ }^{12}$ Despite these advantages, the application of mixed cultures is an underexplored option. ${ }^{15}$ Anticipated challenges are control of the consortium as well as difficulties to find matching fermentation conditions for all involved strains. A consortium for the direct production of ethanol from lignocelluosic biomass may consist of a strain producing the cellulolytic enzymes, a strain fermenting hexoses to ethanol and a strain converting the C5 sugars to ethanol. Industrial cellulase production relies mainly on fungal strains belonging to Trichoderma or Aspergillus species, which require aerobic conditions for efficient enzyme secretion. ${ }^{16}$ The yeast Saccharomyces cerevisiae is commonly applied for ethanol production from glucose or sucrose, however giving high product yields only under anaerobic conditions. ${ }^{17}$ Scheffersomyces (formerly Pichia) stipitis is one of the best natural pentose utilizing organisms and most efficiently produces ethanol under microaerophilic conditions. ${ }^{\mathbf{1 8}, 19}$ Thus for efficient CPB with the mentioned strains, a bioreactor enabling simultaneous aerobic and anaerobic conditions is needed. To this end, we developed a process concept based on locally defined aeration through a membrane (Fig. 2). A dense oxygen permeable membrane serves as a growth basis for different microorganisms, where they form a biofilm. Oxygen necessary for the growth of the fungi and the secretion of cellulolytic enzymes is only delivered from the gas-phase through the membrane, which causes an oxygen gradient within the biofilm. The oxygen saturated zone is located directly on the membrane, whereas the upper part of the biofilm as well as the liquid bulk phase including the biomass are oxygen depleted. The extracellular enzymes secreted in the aerobic part of the biofilm are released into the fermentation slurry and hydrolyse the hemicellulose and cellulose in the biomass to mono-sugars. These sugars are then primarily fermented by the faster growing yeast cells to ethanol in the anaerobic zones of the reactor. Part of the ethanol diffuses through the membrane into the gas phase.

Besides the unique oxygen profile, the proposed reactor concept offers an additional advantage of immobilization of the

Table 1 Summary of the reported performance of some natural and engineered CBP strains to directly ferment cellulosic substrates

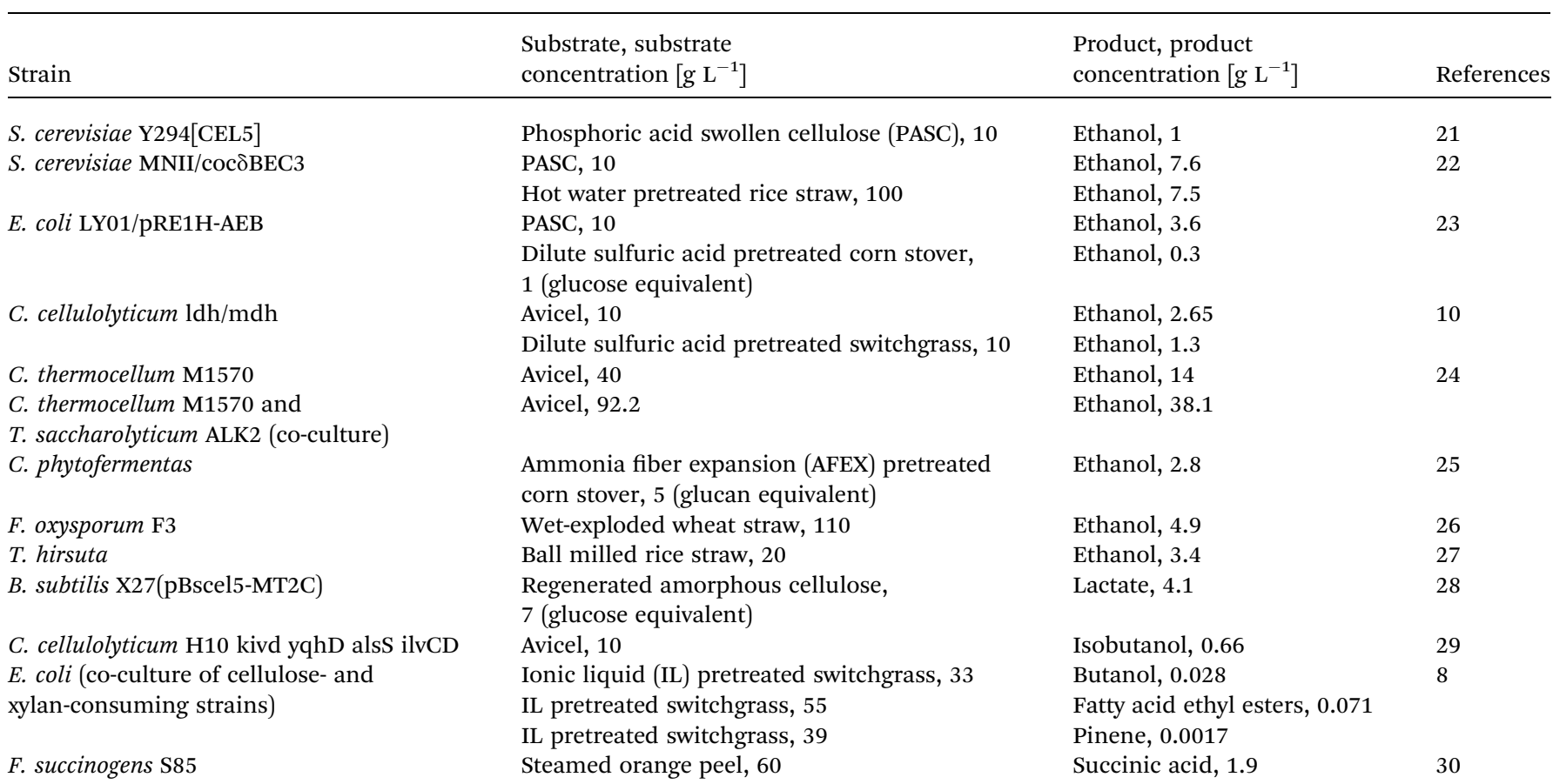




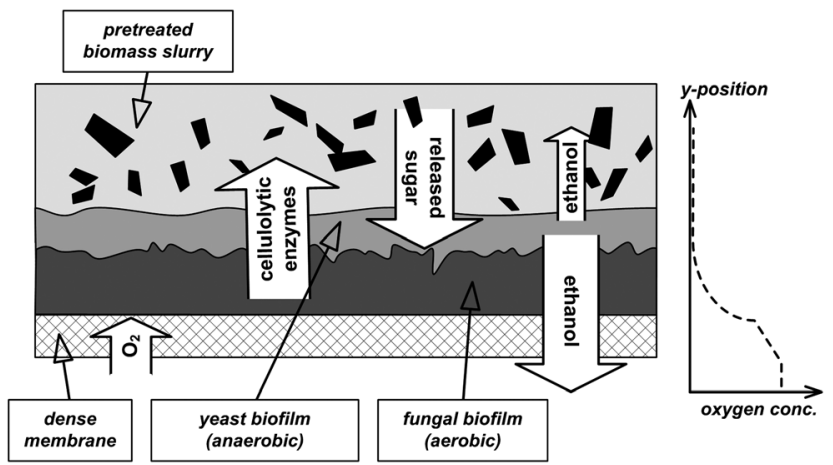

Fig. 2 Concept of the multispecies biofilm membrane reactor. The aerobic, enzyme producing fungi grow directly on the membrane, through which oxygen is supplied. The released enzymes hydrolyze the carbohydrate fraction of the lignocellulosic biomass to soluble sugars, which are metabolized by the ethanol fermenting microorganisms in the anaerobic parts of the reactor. The likely oxygen concentration in the reactor is depicted in the graph on the right hand side.

microbial cells in a biofilm. The biofilm growth mode is associated with increased microbial resistance against toxic substances, reduced cell biomass production and higher productivity. ${ }^{20}$

\section{Results and discussion}

\section{Batch consolidated bioprocesssing of Avicel to ethanol}

For the implementation of the concept we modified commercially available filtration modules to obtain 16 and $32 \mathrm{~mL}$ batch reactors with a vertically installed silicone membrane separating the magnetically stirred fermentation compartment and the gas room. The gas compartment was constantly flushed with air and the off-gas was sent to an online gas chromatograph to quantify the ethanol leaving the system via the membrane.

We used Avicel - a pure microcrystalline cellulose - as the sole carbon source to prove the feasibility of the concept. We first tested three different inoculation schemes. All reactors containing nutrient medium with $17.5 \mathrm{~g} \mathrm{~L}^{-1}$ Avicel were inoculated with the cellulolytic enzyme production strain Trichoderma reesei Rut $\mathrm{C} 30$. The ethanol producing yeast $S$. cerevisiae was added at three different time points: either directly together with the fungi, or 2 and 4 days after fungal inoculation, respectively. In all three inoculation schemes a layered biofilm was formed on the membrane (Fig. 3a) and a similar maximum ethanol concentration of $7.2 \mathrm{~g} \mathrm{~L}^{-1}$ was reached (Fig. 3b). This corresponds to a yield of $73 \%$ based on the total cellulose added to the system, thus including the substrate consumed for fungal growth and cellulase production. In all three cases the maximum ethanol concentration was reached 7 days after fungal inoculation. It is also worth noting that the glucose liberation by cellulose hydrolysis exceeded the glucose demand of $T$. reese $i$ : after 2 and 4 days cultivation of only $T$. reese $i$, glucose concentrations of 1.8 and $5.3 \mathrm{~g} \mathrm{~L}^{-1}$, respectively, were measured in the supernatant. The fact, that the system worked if yeast and fungi, which both thrive under aerobic conditions, are inoculated together, showed the intriguing self-organizational ability of the co-culture. It also proved that $T$. reese $i$ is able to produce cellulolytic enzymes in the presence of yeast cells although they consume most of the sugars.

It should also be mentioned that $\beta$-glucosidase was added to the above described reactions as this enzyme is generally
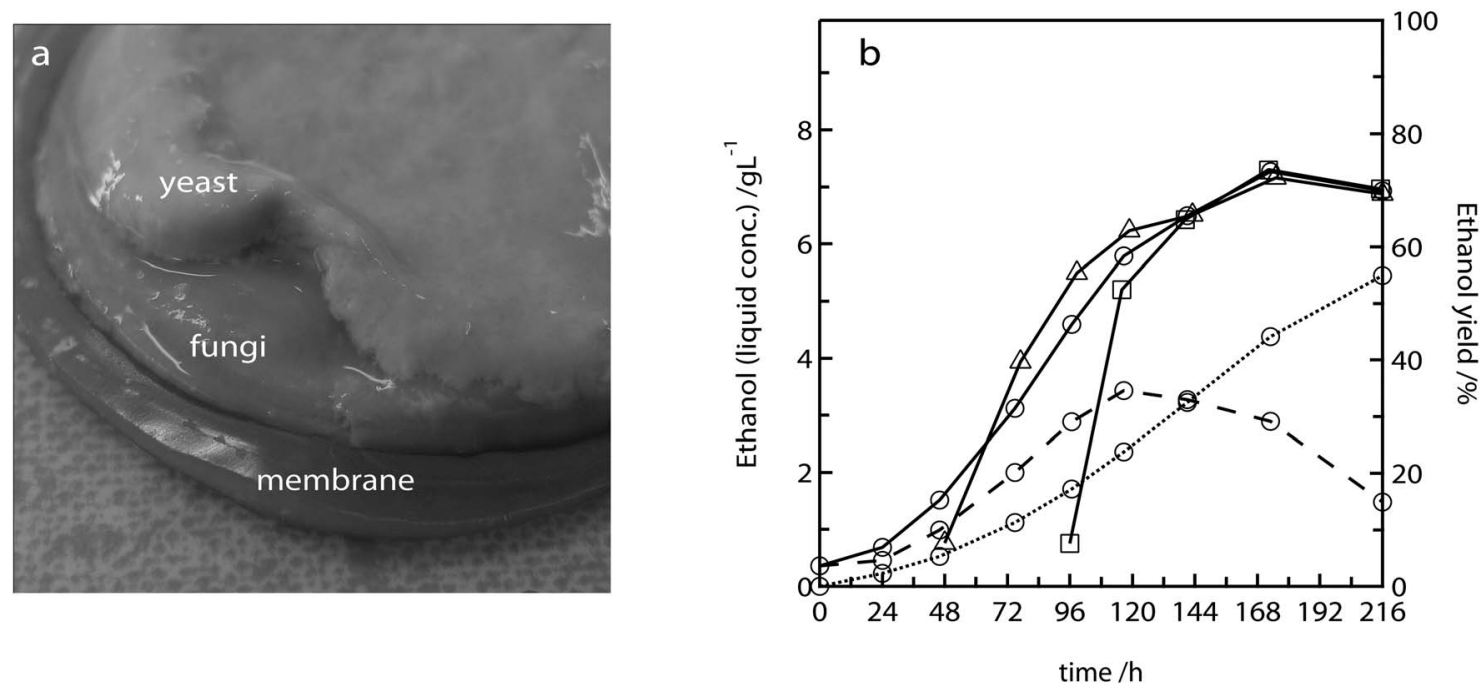

Fig. 3 Consolidated bioprocessing of microcrystalline cellulose to ethanol in the MBM reactor. (a) The picture shows a membrane covered with a two layered biofilm consisting of the T. reesei biofilm directly on the membrane and the $S$. cerevisiae biofilm on top of it. (b) Consolidated bioprocessing of Avicel to ethanol in the MBM reactor. $17.5 \mathrm{~g} \mathrm{~L}^{-1}$ Avicel were added to the MBM reactors together with T. reesei cells and different times of inoculation with S. cerevisiae were tested: at inoculation with $T$. reesei $(O), 2$ days $(\Delta)$ and 4 days after inoculation $(\square)$. $t=0 \mathrm{~h}$ corresponds to the point of inoculation with $T$. reesei cells. The total ethanol concentration (solid line with markers) as well as the ethanol concentration in the liquidphase (dashed line) and in the gas phase recalculated to the corresponding concentration in the liquid phase (dotted line) are shown. The yield is calculated based on the total amount of carbon source available at the inoculation with fungal cells. 
produced only in limited amounts by $T$. reesei Rut C30.31,32 $\beta$-glucosidase cleaves cellobiose to glucose, thereby circumventing the inhibition of cellulose hydrolysis by cellobiose. However, $\beta$-glucosidase has no significant cellulolytic activity. This was demonstrated in a blank experiment where only $\beta$-glucosidase is added to a mixture of Avicel and $S$. cerevisiae. Up to $142 \mathrm{~h}$ no ethanol was produced (Fig. S1†).

The employed silicone membrane is not only permeable for oxygen, but also for ethanol and water. Thus, we always quantified the distribution of ethanol between the gas and the liquid phase and calculated the total ethanol concentration. A complete dataset of the ethanol distribution is depicted in Fig. $3 \mathrm{~b}$. At the end of the experiment with concomitant inoculation, $79 \%$ of ethanol was separated from the liquid phase by diffusion through the membrane into the gas phase. If it were recovered completely from the gas phase together with the codiffusing water (0.0375 $\mathrm{g} \mathrm{h}^{-1}$ employing dry air), a solution containing $19.4 \mathrm{~g} \mathrm{~L}^{-1}$ ethanol would be obtained, which is 2.7 times higher compared to the theoretical final titer of $7.2 \mathrm{~g} \mathrm{~L}^{-1}$ ethanol without diffusion. Complete pre-separation and enrichment of ethanol is very favourable for the further downstream processing, as the costs and energy requirement for distillation decrease exponentially with increasing input ethanol concentration..$^{33}$ The in situ product removal also circumvents cell toxic or enzyme inhibitory effects of high concentrations of ethanol and might become important if a more toxic product such as butanol is produced.

\section{Semi-continuous fermentation of Avicel to ethanol}

To investigate the long-term stability of the system, we performed a semi-continuous experimental run: after a batch phase of $69 \mathrm{~h}, 25 \%$ of the contents of the $16 \mathrm{~mL}$ reactor were

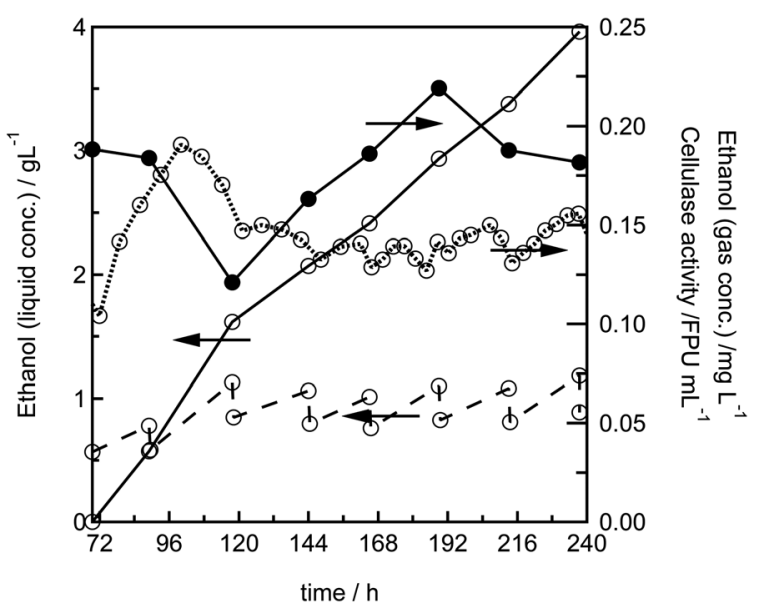

Fig. 4 Semi-continuous ethanol production from Avicel in a $16 \mathrm{~mL}$ MBM reactor: after a batch phase of $69 \mathrm{~h}$, the Avicel concentration was adjusted to $10 \mathrm{~g} \mathrm{~L}^{-1}$ and every $24 \mathrm{~h}$ a quarter of the reaction phase was exchanged against a fresh medium containing $10 \mathrm{~g} \mathrm{~L}^{-1}$ Avicel. The ethanol concentration in the liquid phase (dashed line), the ethanol concentration in the gas phase (dotted line), the cellulase activity ( $)$ and the cumulated total ethanol production during the semi-continuous phase (solid line) are shown. exchanged against fresh fermentation medium every $24 \mathrm{~h}$. Over 7 cycles a steady ethanol production rate could be achieved, showing that the fungal biofilm continuously secretes cellulolytic enzymes, and that the yeast continuously produces ethanol (Fig. 4). This is also reflected by the measurement of the cellulase activity in the fermentation supernatant, which fluctuates around a value of $0.18 \mathrm{FPU} \mathrm{mL} \mathrm{m}^{-1}$, but clearly does not show a constant decrease as it would be expected if there was no enzyme production (Fig. 4).

\section{Fermentation of dilute acid pretreated wheat straw}

After proofing the general feasibility of the MBM concept with the medium containing only Avicel, we switched to dilute acid pretreated wheat straw as the carbon source to get first insights into which level of process integration could be achieved, i.e. can the solid liquid separation, washing and detoxification steps be avoided when using a biofilm based system. Furthermore, the xylose fermenting strain $S$. stipitis was added to the consortium. We directly used the wheat straw slurry obtained after dilute sulfuric acid pretreatment, titrated it with sodium hydroxide to $\mathrm{pH} 5.0$ and diluted it by a factor of approximately 1.5 to obtain a cellulose concentration of $17.5 \mathrm{~g} \mathrm{~L}^{-1}$. To estimate the inhibitory characteristics of the hydrolysate, we also used washed pretreated wheat straw supplemented with the same concentration of xylose as present in the whole slurry experiment. Also, we compared the performance of the MBM system to shake flask based simultaneous saccharification and cofermentation ( $\mathrm{SScF}$ ) using commercially available cellulase and the same yeast strains. In SScF with a co-culture of $S$. cerevisiae and $S$. stipitis, a higher ethanol yield (41\%) was achieved with the washed substrate supplemented with xylose compared to the whole slurry $(38 \%)$, where also more xylose remained unmetabolized (4.6 versus $2.1 \mathrm{~g} \mathrm{~L}^{-1}$, Fig. 5a). This suggests that $S$. stipitis is inhibited by substances in the pretreatment slurry although it is still able to grow. In the MBM system maximum ethanol titers of $9.8 \mathrm{~g} \mathrm{~L}^{-1}(69 \%)$ for the whole slurry fermentation and $9.1 \mathrm{~g} \mathrm{~L} \mathrm{~L}^{-1}$ (63\%) for the washed wheat straw fermentation were reached (Fig. 5b). Xylose is consumed completely during $144 \mathrm{~h}$ of fermentation and the consumption rate is only slightly lower in the whole slurry fermentation. In the MBM system, T. reesei and S. stipitis compete for the available xylose, which can be metabolized by both strains. In the washed substrate experiment, the higher xylose consumption rate in the MBM system compared to SScF can thus also be explained by xylose consumption through $T$. reesei. However, the higher ethanol yield indicates that $S$. stipitis metabolizes most of the xylose despite its comparably low sugar consumption rate. ${ }^{34}$ It is also possible, that $S$. stipitis occupied the microaerobic position in the biofilm and thus found better fermentation conditions in the MBM reactor. For the whole slurry experiment, it is difficult to deduce whether the reason for the lower inhibition of $S$. stipitis in the MBM system is the protective effect of the biofilm growth form or the possible detoxification of the pretreatment slurry by the growing fungi. ${ }^{35}$ In contrast to a mixture of Avicel and xylose as substrates where identical yields were achieved (see Fig. S2†), pretreated wheat 

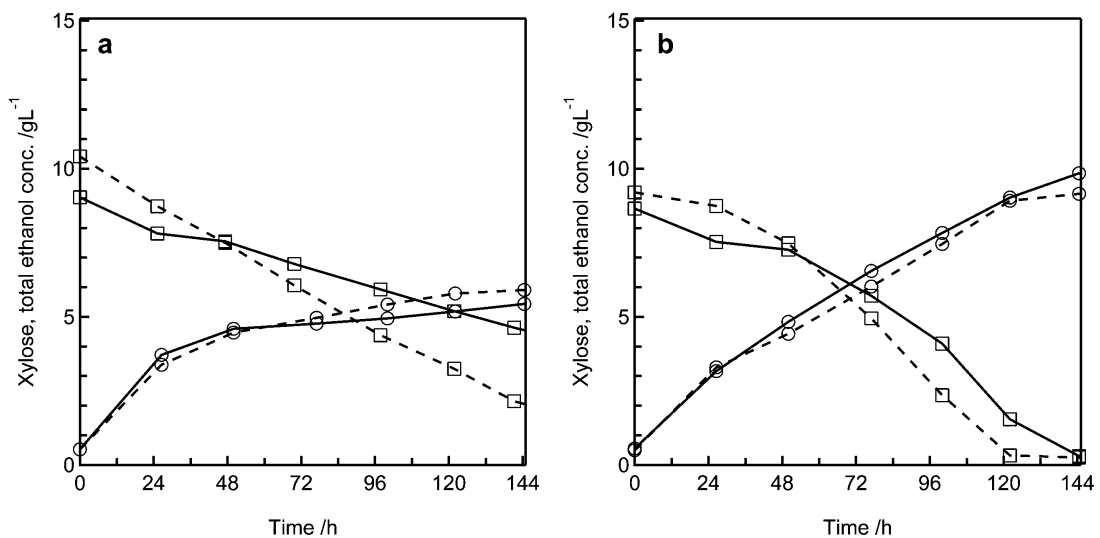

Fig. 5 Commercial enzyme based SScF and consolidated bioprocessing of dilute acid pretreated wheat straw to ethanol. The xylose ( $\square$ ) and total ethanol (O) concentrations are shown. (a) Commercial enzyme based SScF. Whole slurry dilute acid pretreated wheat straw (solid line) and xylose supplemented washed solids of dilute acid pretreated wheat straw (dashed line) containing $17.5 \mathrm{~g} \mathrm{~L}^{-1}$ cellulose were converted to ethanol employing a cellulase loading of $15 \mathrm{FPU} \mathrm{g}_{\text {cellulose }}{ }^{-1}$ and a co-culture of S. cerevisiae and S. stipitis. (b) Consolidated bioprocessing of dilute acid pretreated wheat straw to ethanol in the MBM system employing T. reesei, S. cerevisiae and S. stipitis. Whole slurry dilute acid pretreated wheat straw (solid line) and xylose supplemented washed solids of dilute acid pretreated wheat straw (dashed line) initially containing $17.5 \mathrm{~g} \mathrm{~L}^{-1}$ cellulose were converted to ethanol after addition of yeast cells at day four after fungal inoculation. $t=0$ designates the inoculation with yeast, the fungionly phase is not shown.

straw was utilized more efficiently in the MBM system than in $\mathrm{SScF}$. It is possible that the multi-enzyme cocktail produced by T. reesei is superior for wheat straw digestion as the enzyme production substrate has an influence on the later hydrolytic performance. ${ }^{36,37}$ This can be explained by a transcriptomic response of the fungus to the substrate as has been recently demonstrated by Bischof et al. ${ }^{38}$

\section{Discussion}

The results presented demonstrate the feasibility of the MBM process. The unique feature of combining aerobic and anaerobic conditions in one reactor distinguishes the system from other consortia based CBP approaches. Zuroff et al. combined the obligate anaerobic cellulolytic strain Clostridium phytofermentans and the facultative anaerobic ethanologenic S. cerevisiae cdt-1. Under controlled oxygen delivery a stable symbiotic relationship could be established with the yeast protecting C. phytofermentas from introduced oxygen in return for soluble sugars. However, the hydrolytic capacity of the system was limited. Thus, endoglucanase was added to the consortium that then produced $22 \mathrm{~g} \mathrm{~L}^{-1}$ ethanol from $100 \mathrm{~g} \mathrm{~L}^{-1}$ $\alpha$-cellulose in $400 \mathrm{~h}$. A similar $S$. cerevisiae cdt-1 monoculture produced only $9 \mathrm{~g} \mathrm{~L}^{-1}$ ethanol. ${ }^{39}$ In contrast Minty et al. used a completely aerobic system consisting of $T$. reesei Rut C30 and a recombinant Escherichia coli which produced $1.88 \mathrm{~g} \mathrm{~L}^{-1}$ isopropanol from $20 \mathrm{~g} \mathrm{~L}^{-1}$ pretreated corn stover in $300 \mathrm{~h}$. The total carbohydrate conversion amounted to approximately $50 \%{ }^{40}$ Taken together, the MBM system compares very well with these data as higher conversions and yields have been achieved in shorter runtimes. In order to further advance the MBM system, the addition of $\beta$-glucosidase should be circumvented. One possible strategy to this end would be the application of a more complete cellulase producer or the enhancement of the consisting consortium with a $\beta$-glucosidase producing strain. Alternatively, also the ethanologenic strain could be exchanged to one with a broader substrate spectrum, such as Dekkera bruxxelensis which is able to convert cellobiose to ethanol. ${ }^{41}$ In this case, the addition of $\beta$-glucosidase is unnecessary which has been demonstrated by the achievement of identical fermentation kinetics and ethanol yields as in the $\beta$-glucosidase supported control with S. cerevisiae (Fig. S3†).

Furthermore, a continuous and upscaled MBM process needs to be developed. For a larger scale version of the process we envision a change from the flat sheet membrane to a tubular membrane, which is flushed with air and can be submerged in a standard stirred tank reactor. Similar reactors were applied in cell cultivation or for waste water nitrification/denitrification. ${ }^{42,43}$

\section{Experimental}

\section{Strains, media and inoculum preparation}

Trichoderma reesei Rut C30 (ATCC 56765, IHEM 5652) was purchased from the Scientific Institute of Public Health, BCCM/ IHEM (Brussels, Belgium) as freeze dried spores and was revived according to the instructions. Spores from a 7 day old potato dextrose agar plant culture (Beckton, Dickinson and Company, Le Pont de Claix, France) incubated at $28{ }^{\circ} \mathrm{C}$ were suspended in $5 \mathrm{~mL}$ water, mixed with an equal volume of $40 \%$ glycerol and were stored at $-80{ }^{\circ} \mathrm{C}$. For precultures, $50 \mathrm{~mL}$ Mandels medium containing $7.5 \mathrm{~g} \mathrm{~L}^{-1}$ Avicel (Sigma Aldrich, Buchs, Switzerland) were inoculated with $1 \mathrm{~mL}$ of the above described glycerol stocks and incubated in $500 \mathrm{~mL}$ Erlenmeyer flasks for 4 days at $28{ }^{\circ} \mathrm{C}$ and $200 \mathrm{rpm}$. Mandels medium contained the following ingredients (in $\mathrm{g} \mathrm{L}^{-1}$ ): $\mathrm{KH}_{2} \mathrm{PO}_{4}, 2$; $\left(\mathrm{NH}_{4}\right)_{2} \mathrm{SO}_{4}, 1.4 ; \mathrm{MgSO}_{4} \cdot 7 \mathrm{H}_{2} \mathrm{O}, 0.3 ; \mathrm{CaCl}_{2} \cdot 6 \mathrm{H}_{2} \mathrm{O}, 0.4$; urea, 0.3; peptone, 0.75; yeast extract, 0.25 ; and $1 \mathrm{~mL} \mathrm{~L}^{-1}$ trace element stock. The trace element stock contained (in $\mathrm{g} \mathrm{L}^{-1}$ ): 
$\mathrm{FeSO}_{4} \cdot 7 \mathrm{H}_{2} \mathrm{O}, 5 ; \mathrm{MnSO}_{4} \cdot \mathrm{H}_{2} \mathrm{O}, 1.6 ; \mathrm{ZnSO}_{4} \cdot 7 \mathrm{H}_{2} \mathrm{O}, 1.4 ; \mathrm{CoCl}_{2} \cdot 6$ $\mathrm{H}_{2} \mathrm{O}, 3.7$ and $10 \mathrm{~mL} \mathrm{~L}^{-1}$ concentrated hydrochloric acid and was sterile filtered. To avoid precipitation, $100 \times \mathrm{CaCl}_{2}$ and $\mathrm{MgSO}_{4}$ solutions were autoclaved separately before combining them with the remaining ingredients, called Mandels base medium, below.

For Saccharomyces cerevisiae (VTT C-79095) precultures, $30 \mathrm{~mL}$ of YPD medium (in $\mathrm{g} \mathrm{L}^{-1}$ : yeast extract, 10; peptone, 20; dextrose, 10) were inoculated with $0.3 \mathrm{~mL}$ of $20 \%$ glycerol stocks and incubated overnight in $250 \mathrm{~mL}$ Erlenmeyer flasks at $28{ }^{\circ} \mathrm{C}$ and $200 \mathrm{rpm}$. Scheffersomyces stipitis (VTT C-07806T) was cultured similarly but using YM medium containing (in $\mathrm{g} \mathrm{L}^{-1}$ ): yeast extract, 3 ; malt extract, 3 ; peptone, 5 and dextrose, 10.

\section{Feedstock and pretreatment method}

Wheat straw was harvested and baled in 2010 and was obtained from the Brethauer farm (Bad Gandersheim, Germany). It had a dry matter content of $94.4 \%$ and contained $22.0 \%$ xylan, $35.9 \%$ glucan and $22.0 \%$ lignin on a dry basis as determined by quantitative saccharification. ${ }^{\mathbf{4 4}}$ The straw was reduced in size with a cutting mill (Retsch SM100, Retsch GmbH, Haan, Germany) equipped with a bottom screen ( $2 \mathrm{~mm}$ trapezoid holes) and sieved to a fraction containing particles between 0.18 and $0.5 \mathrm{~mm}$ of size. Particles larger than $0.5 \mathrm{~mm}$ were reground through a $0.5 \mathrm{~mm}$ bottom screen and sieved again. The fractions containing particles between 0.18 and $0.5 \mathrm{~mm}$ of size were combined and subjected to pretreatment.

Pretreatment was carried out at $140{ }^{\circ} \mathrm{C}$ for $20.5 \mathrm{~min}$ with a wheat straw loading of $7.5 \% \mathrm{w} / \mathrm{w}$ and a sulfuric acid concentration of $1 \% \mathrm{w} / \mathrm{w}$ (based on the total liquid in the reactor) in an electrically heated high pressure $300 \mathrm{~mL}$ autoclave made of titanium (Premex reactor AG, Lengnau, Switzerland). After pretreatment, the slurry was titrated to $\mathrm{pH} 5.0$ with $50 \% \mathrm{NaOH}$ solution and contained $29 \mathrm{~g} \mathrm{~L}^{-1}$ glucan $\left(27 \mathrm{~g} \mathrm{~L}^{-1}\right.$ thereof in the solid phase) and $22 \mathrm{~g} \mathrm{~L}^{-1}$ xylose (18.5 $\mathrm{g} \mathrm{L}^{-1}$ in the liquid phase). Optionally, the pretreated wheat straw was washed three times by centrifugation, decantation and resuspension in deionized water to the original weight.

\section{MBM reactor}

The membrane bioreactors were adapted from commercially available reusable polysulfone filter units (300-4000, Nalgene, Rochester, NY, USA). A circular (50 mm diameter), dense polydimethylsiloxane (PDMS) membrane with a thickness of $50 \mu \mathrm{m}$ (OPV-2551s-30n, CM-CELFA, Schwyz, Switzerland) was installed vertically, which separated the reaction phase and the gas phase. Custom made polysulfone inserts reduced the volume of the magnetically stirred liquid phase to 16 and $32 \mathrm{~mL}$, respectively. The gas compartment was flushed with humidified air

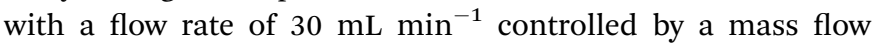
controller (red-y compact, Vögtlin Instruments AG, Aesch, Switzerland). The off-gas was sent via a heated transfer line $\left(35{ }^{\circ} \mathrm{C}\right)$ to a custom-made autosampler rack and was analyzed every $6 \mathrm{~h}$ for its ethanol content by gas chromatography. The membrane reactor was placed in an incubator with a temperature of $28{ }^{\circ} \mathrm{C}$. Liquid samples were withdrawn under sterile, well-mixed conditions through 14 gauge stainless steel needles.

\section{Batch membrane reactor fermentations}

For batch membrane reactor fermentations, the $32 \mathrm{~mL}$ reactor was filled with Mandels base medium containing $17.5 \mathrm{~g} \mathrm{~L}^{-1}$ Avicel and autoclaved for $20 \mathrm{~min}$ at $121{ }^{\circ} \mathrm{C}$. The remaining medium ingredients were added and the reactor was inoculated with $5 \% \mathrm{v} / \mathrm{v} T$. reesei preculture. The specified yeast strains (S. cerevisiae and $S$. stipitis) were inoculated 0 to $96 \mathrm{~h}$ after fungal inoculation to an optical density at $600 \mathrm{~nm}\left(\mathrm{OD}_{600}\right)$ of 0.5 for each strain. Together with the yeast, corn steep liquor and $\beta$-glucosidase (Novozymes 188, Novozymes, Denmark) were added. The final concentration of corn steep liquor was $3 \mathrm{~g} \mathrm{~L}^{-1}$ and $\beta$-glucosidase activity was $30 \mathrm{CBU} \mathrm{g}_{\text {glucan }}{ }^{-1}$. The time of yeast inoculation is stated in the main text.

\section{Semicontinuous conversion of Avicel to ethanol}

In a $16 \mathrm{~mL}$ reactor, $T$. reesei was grown on Mandels medium containing $7.5 \mathrm{~g} \mathrm{~L}^{-1}$ Avicel as a carbon source for 4 days. Then, similar to the above described method, yeast cells, corn steep liquor and $\beta$-glucosidase were added together with $10 \mathrm{~g} \mathrm{~L}^{-1}$ Avicel. After a batch phase of $69 \mathrm{~h}$ the Avicel concentration was readjusted to $10 \mathrm{~g} \mathrm{~L}^{-1}$ and then every $24 \mathrm{~h}$ a quarter of the reaction phase was exchanged against fresh Mandels medium containing $10 \mathrm{~g} \mathrm{~L}^{-1}$ Avicel, $3 \mathrm{~g} \mathrm{~L}^{-1}$ corn steep liquor and $\beta$-glucosidase (30 CBU $\mathrm{g}_{\text {cellulose }}{ }^{-1}$ ). Ethanol concentration in the liquid phase was measured by HPLC before the medium exchange and was calculated based on the dilution after the exchange.

\section{Simultaneous saccharification and co-fermentation}

Simultaneous saccharification and co-fermentation experiments were performed in $125 \mathrm{~mL}$ Erlenmeyer flasks that contained a total reaction mass of $25 \mathrm{~g}$ and were placed on a shaking incubator featuring a throw of $25 \mathrm{~mm}$ (Minitron, Infors-HT, Bottmingen, Switzerland) that rotated at $150 \mathrm{rpm}$ at $28{ }^{\circ} \mathrm{C}$. The flasks were closed using screw caps with apertures together with PTFE-lined silicone septa and vented through 20gauge needles (VWR, Dietikon, Switzerland) covered with aluminum foil. An enzyme loading of 15 FPU $g_{\text {glucan }}{ }^{-1}$ and $30 \mathrm{CBU} \mathrm{g}_{\text {glucan }^{-1}}$ was applied using Spezyme CP cellulase (Genencor International, B.V., Leiden, Netherlands) and Novozymes 188. Otherwise the conditions were identical to the MBM experiments with regard to medium, substrate concentration and microorganisms.

\section{Analytical methods}

Ethanol, glucose, xylose and cellobiose in the liquid phase were quantified by high performance liquid chromatography (Waters 2695 Separation Module, Waters Corporation, Milford, MA, USA) using an Aminex HPX-87H column (Bio-Rad, Hercules, CA, USA) at $60{ }^{\circ} \mathrm{C}$ with $5 \mathrm{mM} \mathrm{H}_{2} \mathrm{SO}_{4}$ as the mobile phase and a refractive index detector (Waters 410). Ethanol in the gas phase 
was determined by gas chromatography (Varian V3800, Varian Analytical Instruments, Walnut Creek, CA, USA, now Agilent Technologies Inc.) using a Zebron ZB-624 column (Phenomenex, Torrance, CA, USA) heated to $40{ }^{\circ} \mathrm{C}$ and a flame ionization detector set to $200{ }^{\circ} \mathrm{C}$. Nitrogen flowing at $5 \mathrm{~mL} \mathrm{~min}{ }^{-1}$ was used as a carrier gas and the split rate was set to 20 . For calibration, nitrogen supplemented with 470 ppm ethanol (PanGas AG, Dagmersellen, Switzerland) was employed.

Cellulase activity expressed in filter paper units (FPU) was measured according to Ghose. ${ }^{45}$

\section{Conclusions}

Taken together, the results presented herein demonstrate the unique potential of the MBM process as high ethanol yields and titers of up to $10 \mathrm{~g} \mathrm{~L}^{-1}$ could be achieved from undetoxified dilute acid pretreated wheat straw slurry although further optimization work regarding e.g. the media or the microorganisms is pending. Industrially proven robust microorganisms for cellulase production and anaerobic sugar fermentation could be combined using MBM technology to produce a wide range of cellulosic chemicals. Furthermore, the current achievements in heterologous biofuel production based on soluble sugars ${ }^{\mathbf{4 6 , 4 7}}$ could be moved efficiently to the more advanced cellulosic stage, especially as the biofilm growth modus is presumably very beneficial for the less robust engineered organisms.

\section{Acknowledgements}

This work was supported in part by the Swiss National Science Foundation grant PZ00P2_121934/1. We thank P. Rudolf von Rohr for supporting this work by providing essential infrastructure and partly paying the salary of S. B.

\section{Notes and references}

1 P. A. M. Claassen, J. B. van Lier, A. M. L. Contreras, E. W. J. van Niel, L. Sijtsma, A. J. M. Stams, S. S. de Vries and R. A. Weusthuis, Appl. Microbiol. Biotechnol., 1999, 52, 741.

2 M. E. Himmel, S.-Y. Ding, D. K. Johnson, W. S. Adney, M. R. Nimlos, J. W. Brady and T. D. Foust, Science, 2007, 315, 804.

3 G. Stephanopoulos, Science, 2007, 315, 801.

4 K. A. Gray, L. S. Zhao and M. Emptage, Curr. Opin. Chem. Biol., 2006, 10, 141.

5 C. C. Geddes, I. U. Nieves and L. O. Ingram, Curr. Opin. Biotechnol., 2011, 22, 312.

6 C. E. Wyman, Trends Biotechnol., 2007, 25, 153.

7 D. G. Olson, J. E. McBride, A. J. Shaw and L. R. Lynd, Curr. Opin. Biotechnol., 2012, 23, 396.

8 G. Bokinsky, P. P. Peralta-Yahya, A. George, B. M. Holmes, E. J. Steen, J. Dietrich, T. S. Lee, D. Tullman-Ercek, C. A. Voigt, B. A. Simmons and J. D. Keasling, Proc. Natl. Acad. Sci. U. S. A., 2011, 108, 19949.

9 J. E. Hyeon, W. J. Jeon, S. Y. Whang and S. O. Han, Enzyme Microb. Technol., 2011, 48, 371.
10 Y. Li, T. J. Tschaplinski, N. L. Engle, C. Y. Hamilton, M. Rodriguez, Jr, J. C. Liao, C. W. Schadt, A. M. Guss, Y. Yang and D. E. Graham, Biotechnol. Biofuels, 2012, 5, 2.

11 D. B. Jordan, M. J. Bowman, J. D. Braker, B. S. Dien, R. E. Hector, C. C. Lee, J. A. Mertens and K. Wagschal, Biochem. J., 2012, 442, 241.

12 H. Alper and G. Stephanopoulos, Nat. Rev. Microbiol., 2009, 7, 715.

13 W. Sabra, D. Dietz, D. Tjahjasari and A.-P. Zeng, Eng. Life Sci., 2010, 10, 407.

14 T. R. Zuroff and W. R. Curtis, Appl. Microbiol. Biotechnol., 2012, 93, 1423.

15 R. Kleerebezem and M. C. M. van Loosdrecht, Curr. Opin. Biotechnol., 2007, 18, 207.

16 J. J. Rautio, B. A. Smit, M. Wiebe, M. Penttila and M. Saloheimo, BMC Genomics, 2006, 7, 247.

17 J. M. Laplace, J. P. Delgenes, R. Moletta and J. M. Navarro, Appl. Microbiol. Biotechnol., 1991, 36, 158.

18 S. R. Hughes, W. R. Gibbons, S. S. Bang, R. Pinkelman, K. M. Bischoff, P. J. Slininger, N. Qureshi, C. P. Kurtzman, S. Liu, B. C. Saha, J. S. Jackson, M. A. Cotta, J. O. Rich and J. E. Javers, J. Ind. Microbiol. Biotechnol., 2012, 39, 163.

19 T. W. Jeffries, I. V. Grigoriev, J. Grimwood, J. M. Laplaza, A. Aerts, A. Salamov, J. Schmutz, E. Lindquist, P. Dehal, H. Shapiro, Y. S. Jin, V. Passoth and P. M. Richardson, Nat. Biotechnol., 2007, 25, 319.

20 N. Qureshi, B. A. Annous, T. C. Ezeji, P. Karcher and I. S. Maddox, Microb. Cell Fact., 2005, 4, 24.

21 R. den Haan, S. H. Rose, L. R. Lynd and W. H. van Zyl, Metab. Eng., 2007, 9, 87.

22 R. Yamada, N. Taniguchi, T. Tanaka, C. Ogino, H. Fukuda and A. Kondo, Biotechnol. Biofuels, 2011, 4, 8.

23 S. Ryu and M. N. Karim, Appl. Microbiol. Biotechnol., 2011, 91, 529.

24 D. A. Argyros, S. A. Tripathi, T. F. Barrett, S. R. Rogers, L. F. Feinberg, D. G. Olson, J. M. Foden, B. B. Miller, L. R. Lynd, D. A. Hogsett and N. C. Caiazza, Appl. Environ. Microbiol., 2011, 77, 8288.

25 M. J. Jin, V. Balan, C. Gunawan and B. E. Dale, Biotechnol. Bioeng., 2011, 108, 1290.

26 G. Panagiotou, E. Topakas, M. Moukouli, P. Christakopoulos and L. Olsson, Biomass Bioenergy, 2011, 35, 3727.

27 K. Okamoto, Y. Nitta, N. Maekawa and H. Yanase, Enzyme Microb. Technol., 2011, 48, 273.

28 X. Z. Zhang, N. Sathitsuksanoh, Z. G. Zhu and Y. H. P. Zhang, Metab. Eng., 2011, 13, 364.

29 W. Higashide, Y. C. Li, Y. F. Yang and J. C. Liao, Appl. Environ. Microbiol., 2011, 77, 2727.

30 Q. A. Li, J. A. Siles and I. P. Thompson, Appl. Microbiol. Biotechnol., 2010, 88, 671.

31 K. Kovacs, L. Megyeri, G. Szakacs, C. P. Kubicek, M. Galbe and G. Zacchi, Enzyme Microb. Technol., 2008, 43, 48.

32 R. R. Singhania, R. K. Sukumaran, A. K. Patel, C. Larroche and A. Pandey, Enzyme Microb. Technol., 2010, 46, 541.

33 L. M. Vane, Biofuels, Bioprod. Biorefin., 2008, 2, 553. 
34 F. M. Girio, C. Fonseca, F. Carvalheiro, L. C. Duarte, S. Marques and R. Bogel-Lukasik, Bioresour. Technol., 2010, 101, 4775.

35 W. Parawira and M. Tekere, Crit. Rev. Biotechnol., 2011, 31, 20.

36 H. Jorgensen and L. Olsson, Enzyme Microb. Technol., 2006, 38, 381.

37 B. Sipos, Z. Benko, D. Dienes, K. Reczey, L. Viikari and M. Siika-aho, Appl. Biochem. Biotechnol., 2010, 161, 347.

38 R. Bischof, L. Fourtis, A. Limbeck, C. Gamauf, B. Seiboth and C. P. Kubicek, Biotechnol. Biofuels, 2013, 6, 127.

39 T. R. Zuroff, S. Barri Xiques and W. R. Curtis, Biotechnol. Biofuels, 2013, 6, 59.

40 J. J. Minty, M. E. Singer, S. A. Scholz, C.-H. Bae, J.-H. Ahn, C. E. Foster, J. C. Liao and X. N. Lin, Proc. Natl. Acad. Sci. U. S. A., 2013, 110, 14592.
41 D. D. Spindler, C. E. Wyman, K. Grohmann and G. P. Philippidis, Biotechnol. Lett., 1992, 14, 403.

42 H. N. Qi, C. T. Goudar, J. D. Michaels, H.-J. Henzler, G. N. Jovanovic and K. B. Konstantinov, Biotechnol. Prog., 2003, 19, 1183.

43 B. Walter, C. Haase and N. Räbiger, Water Res., 2005, 39, 2781.

44 A. Sluiter, B. R. Hames, R. Ruiz, C. Scarlata, J. Sluiter, D. Templeton and D. Crocker, Determination of structural carbohydrates and lignin in biomass, Golden, CO, USA, 2008. 45 T. K. Ghose, Pure Appl. Chem., 1987, 59, 257.

46 M. R. Connor and J. C. Liao, Curr. Opin. Biotechnol., 2009, 20, 307. 47 J. W. Lee, D. Na, J. M. Park, J. Lee, S. Choi and S. Y. Lee, Nat. Chem. Biol., 2012, 8, 536. 